\title{
Coronary blood supply of the inferior wall of the right ventricle in hearts with Ebstein malformation: relevance to vertical plication
}

\author{
Iki Adachi, MD, ${ }^{\text {a }}$ Siew Yen Ho, PhD, FRCPath, FESC, ${ }^{\text {a }}$ Karen P. McCarthy, BS, ${ }^{\text {a }}$ and Hideki Uemura, MD, FRCS ${ }^{\mathrm{b}}$
}

Objective: Vertical plication of the atrialized chamber in Ebstein malformation has been subject to debate. A major argument against it is risk of coronary arterial injury; however, the coronary anatomy in the malformation remains incompletely investigated.

Methods: We examined 17 autopsied hearts with the malformation. Special attention was paid to the coronary blood supply of the right ventricular inferior wall, focusing on the course of the posterior descending branch and its relationship with the interventricular septum.

Results: The right coronary artery was dominant in 11 cases $(65 \%)$; the remaining 6 had left dominance. In 6 right-dominant hearts, the right coronary artery gave rise to the branch before reaching the crux of the heart. This early takeoff caused the entire branch to be deviated rightward. Another 2 right-dominant hearts showed rightward deviation of the branch course after an initial short segment along the septum. In contrast, in 2 left-dominant hearts, the left circumflex artery ran beyond the crux and then gave rise to the branch, again resulting in rightward deviation of the branch. These deviations allowed the branch to run on the thin walled part of the right ventricular inferior wall where endocardial stitches are placed during typical vertical plication.

Conclusion: The posterior descending branch was frequently $(10 / 17,59 \%)$ deviated toward the right side relative to the interventricular septum in hearts with Ebstein malformation. Because of this and the thinness of the atrialized ventricular wall, care should be taken to the branch even with superficial endothelial stitches.

Ebstein malformation of the tricuspid valve is a relatively rare congenital heart defect with a spectrum of pathologic features. ${ }^{1-3}$ Because surgical management for this entity depends on the anatomic severity of the lesion, several repair methods have been advocated. Among them, the Carpentier method $^{4,5}$ and its modifications ${ }^{6,7}$ are unique in their technique of right ventricular plication. These procedures are characterized by vertical plication of the atrialized ventricular wall, in which the right ventricle is plicated longitudinally along the long axis of the right ventricle (inlet to apex). The vertical plication is thought to restore the shape, and thus possibly the performance, of the right ventricle in a better way than the classic Hunter-Lillehei-Hardy method, which uses a horizontal plication technique in which the right ventricle is plicated transversely, thereby decreasing the long-axis length of the right ventricle.

\footnotetext{
From the Cardiac Morphology Unit, Imperial College London, National Heart \& Lung Institute, ${ }^{\mathrm{a}}$ and the Department of Cardio-Thoracic Surgery, Royal Brompton and Harefield NHS Trust, ${ }^{\mathrm{b}}$ London, UK.

Supported by the Francis Fontan Prize of the European Association of Cardio-Thoracic Surgery (I.A.) and a grant from The Uehara Memorial Foundation. The Cardiac Morphology Unit receives funding from the Royal Brompton and Harefield Hospital Charitable Fund.

Received for publication Jan 9, 2008; revisions received April 16, 2008; accepted for publication June 15, 2008

Address for reprints: Siew Yen Ho, PhD, FRCPath, FESC, Reader in Cardiac Morphology/Honorary Consultant, National Heart \& Lung Institute, Imperial College London, Guy Scadding Building, DoveHouse St, London SW3 6LY, UK (E-mail: yen.ho@imperial.ac.uk).

J Thorac Cardiovasc Surg 2008;136:1437-41

$0022-5223 / \$ 34.00$

Copyright $(c) 2008$ by The American Association for Thoracic Surgery

doi:10.1016/j.jtcvs.2008.06.029
}

The major concern regarding vertical plication, however, is the risk of coronary arterial injury. ${ }^{8-10}$ Despite the critical importance of coronary arterial anatomy in this evaluation, the distribution of variant coronary arterial patterns in Ebstein malformation has not been well studied. With this in mind, we investigated the coronary arterial blood supply of the inferior wall of the right ventricle, with special emphasis on its surgical relevance to vertical plication procedures.

\section{MATERIALS AND METHODS}

This study was approved by the ethics committee of the Royal Brompton Hospital, London, UK. In the cardiac specimens archive of the Royal Brompton Hospital, we found 37 hearts with the feature of Ebstein malformation of the atrioventricular valve. For the purpose of this study, we excluded 20 hearts: 13 with congenitally corrected transposition of the great arteries, 6 with coexisting pulmonary atresia with intact ventricular septum, and 1 in which most of the right ventricular wall had been removed for histologic analysis. The remaining 17 hearts were examined. Patient ages at the time of death ranged from 3 days to 56 years. Of these patients, 2 had undergone replacement of the tricuspid valve with bioprostheses, 4 had undergone closure of atrial septal defect (with an interventional device in 1 case), and 1 had undergone tricuspid annuloplasty with a polytetrafluoroethylene felt strip. After routine examination of gross morphologic characteristics, attention was paid to the coronary blood supply of the inferior wall of the right ventricle, with special focus on the course of the posterior descending branch in relation to the interventricular septum. We defined the posterior descending branch as the largest branch of the inferior ventricular wall arising from the area of the crux of the heart and extending toward the apex. When the right coronary artery gave rise to the branch, it was categorized as having a right-dominant pattern. If the posterior descending branch was a continuation of the left coronary system, the coronary pattern was considered left dominant. 


\section{RESULTS}

\section{Valvular Structure and Associated Lesions}

Apart from 2 hearts in which the tricuspid valve had been replaced, we found the hallmark feature of Ebstein malformation of downward displacement of the tricuspid valve in all hearts. The displacement was minimal in 2 hearts in which both septal and mural leaflets were well developed and the displacement was confined only to the septal leaflet. Except for those 2 hearts, it was not possible to distinguish three valvular leaflets as in hearts with normal structure.

In 6 hearts, a small component corresponding to the septal leaflet was recognizable. This septal component had short and thickened free edge, and its hinge point was moderately displaced distal to the true atrioventricular junction. In 4 hearts, the mural component was absent. In the remaining 2 , the mural component was barely developed and appeared only as a small fibromuscular flap.

In the 6 most severe cases, the trifoliate arrangement of the valvular leaflets was totally effaced. The septal and mural components were smooth, devoid of tendinous cords or papillary muscles. There was no separation of leaflets from the ventricular walls apart from a small portion toward the ventricular apex. As a consequence, the inlet part appeared like a smooth sac. The anterosuperior component was the only tissue that resembled a valvular leaflet. It was hinged at the atrioventricular junction, but its distal margin was continuous with the mural and septal components. Single or multiple fenestrations were observed either between its medial free edge and the ventricular septum or in the anterosuperior leaflet itself as the communication between inlet and outlet portions of the right ventricle.

\section{Coronary Arterial Anatomy}

The results of the coronary arterial anatomy examinations are depicted in Figure 1. A right-dominant coronary pattern was found in 11 hearts $(65 \%)$. In 3 of these, the posterior descending branch ran exactly on the septum in the interventricular groove ( $R$ - 1 group in Figure 1$)$. In contrast, the remaining 8 showed rightward deviation of the branch. This deviation occurred in two ways. First, 2 hearts showed rightward deviation of the branch course after initial short segment along the septum ( $R-2$ group in Figure 1). Second, in the other 6 the right coronary artery gave rise to the branch before reaching the crux of the heart ( $R-3$ group in Figure 1$)$. This early take-off displaced the entire epicardial course of the posterior descending branch to the inferior wall of the right ventricle.

Six hearts $(35 \%)$ had a left-dominant coronary pattern. One had the branch running exactly on the septum in the interventricular groove ( $L-1$ group in Figure 1$)$. In the other 2, the left circumflex artery ran beyond the crux of the heart and then gave rise to the branch, resulting in rightward deviation pattern ( $L-2$ group in Figure 1). In the remaining 3 hearts with a left-dominant pattern, the branch arose before the cir- cumflex artery reached the crux, thus resulting in leftward deviation ( $L-3$ group in Figure 1$)$.

\section{DISCUSSION}

In 1988, Carpentier and associates ${ }^{4}$ presented the original report about an innovative technique for Ebstein malformation in which the tricuspid valve is repaired with concomitant vertical plication of the atrialized portion of the right ventricle. In that article, they emphasized that not only tricuspid insufficiency but also right ventricular dysfunction was an important prognostic factor in disability. To address the latter problem, they introduced vertical plication of the atrialized ventricle. In contrast to the classic horizontal plication by the Hunter-Lillehei-Hardy method, the new approach appeared to restore the shape, and thus possibly performance, of the right ventricle in a better way. The Parisian group attributed their markedly improved surgical result to a synergistic effect from the effective repair of the tricuspid valve and improved right ventricular function. Since then, the Carpentier method has gained popularity, leading to the development of modifications. ${ }^{6,7}$

Controversy still exists, however, regarding this kind of procedure. Some German groups have advocated repair techniques without right ventricular plication. ${ }^{8-10}$ One of their arguments regarding ventricular plication is the lack of hard evidence for improved right ventricular performance after exclusion of the atrialized chamber. Rather, Ullmann and colleagues ${ }^{10}$ have insisted that preservation of the atrialized portion is preferable after reimplantation of the tricuspid leaflets onto the true atrioventricular junction, according to the assumption that the atrialized portion would regain its wall thickness and strength once normal pressure load was imposed. ${ }^{11}$ Another argument for not using any plication procedure, one that is presumably more important, is the risk of interference with coronary circulation, particularly the posterior descending branch, as a result of either direct injury, stenosis, or kinking. Surgeons who have adopted vertical plication have described in their articles how coronary injury could be avoided by placing very superficial, endothelial stitches. ${ }^{4-7}$ The inferior wall of the atrialized portion, however, is usually thin. It is therefore questionable whether such superficial stitches, however meticulously placed, could entirely eliminate the risk of injury to vessels running along extremely thin atrialized walls. No article has mentioned the absence or presence of ischemic change of the myocardium during the early postoperative period. In these circumstances, it is the anatomy of coronary artery and its spatial relationship with the atrialized portion of the right ventricle that should provide insights into this important issue.

Our observation demonstrates unusual characteristic features of the coronary arterial system in hearts with Ebstein malformation. The high prevalence of the left-dominant coronary artery (35\%) found in our series is consistent with that of a previous report ${ }^{3}$ that mainly used specimens from the 


\section{Right Dominant Pattern}

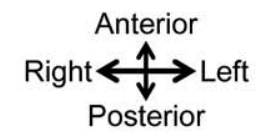

$R-1$. Exactly on the septum
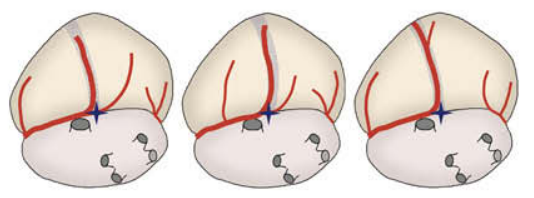

\section{R-2. Rightward deviation} (late deviation)

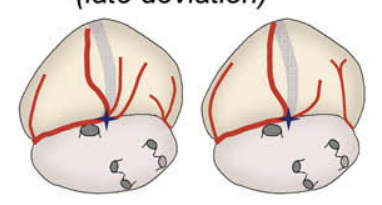

R-3. Rightward deviation (early deviation)
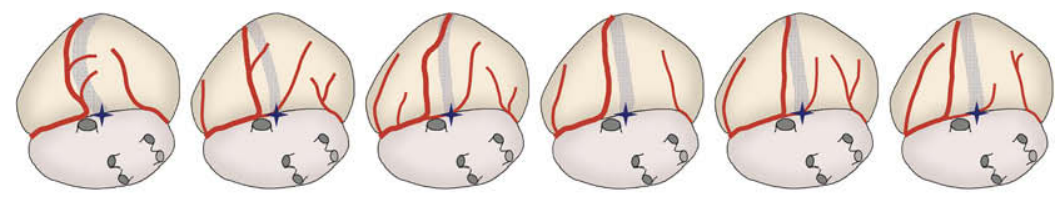

\section{Left Dominant Patterns}

\section{L-1. Exactly on the septum}

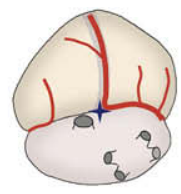

\section{L-2. Rightward deviation}
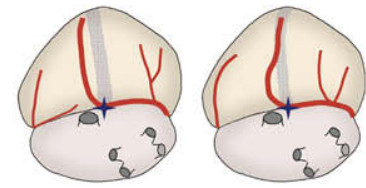

\section{L-3. Leftward deviation}
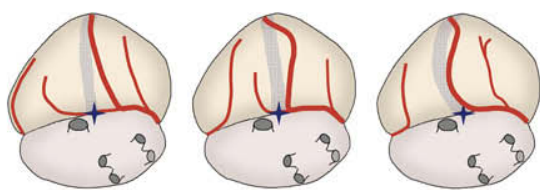

Interventricular septum

$\uparrow$ Crux of the heart

FIGURE 1. Diagram of inferior (diaphragmatic) surface of heart, seen by lifting up cardiac apex to show coronary arterial blood supply of inferior ventricular wall.

same archive. This finding is in marked contrast to the estimated $10 \%$ anticipated in the population with normally structured hearts. ${ }^{12}$ We do not know the reason for higher prevalence of the left-dominant coronary artery in our population with Ebstein malformation. It does not seem to be associated with either the severity of the tricuspid lesion or the degree of right ventricular deformity.

Of particular note for surgeons, especially those who use vertical plication, is the finding that the posterior descending branch did not always run exactly on the interventricular septum. Rather, the branch frequently diverged from the septum toward either the right or left side. Among the hearts with a right-dominant pattern, rightward deviation was found in $73 \%$ (8/11 hearts). This occurred in two ways. In 2 hearts, the branch was deviated toward the right side after passing the crux of the heart. In the other 6 hearts, the branch took off before reaching the crux. In the former type, the deviated portion tended to be somewhat distant from the atrio- ventricular groove. In contrast, the early takeoff seen in the latter type affected not only the distal portion but also the proximal portion of the branch. The latter form of rightward deviation should be of critical importance in a plication procedure, because such procedures usually require stitches placed on the inferior wall of the right ventricle at a proximal area from the atrioventricular junction. Surprisingly, the rightward deviation of the branch was found fairly frequently $(33 \%, 2 / 6$ hearts $)$, even in hearts with a left-dominant coronary pattern. In these hearts, the circumflex artery ran along the atrioventricular groove beyond the crux and then gave rise to the branch. In this setting, the proximal portion of the branch had rightward deviation, as in the case of the early takeoff right-dominant pattern, and thus would have been at risk during plication.

If the morphology of hearts with typical Ebstein malformation, in which both septal and mural components show downward displacement, is examined carefully, we can appreciate 
"free wall" plication
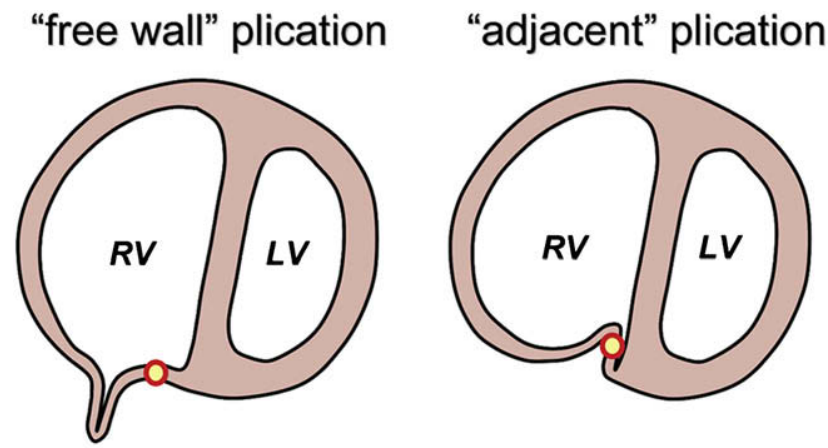

O Posterior descending branch

FIGURE 2. Schematic illustrations of ventricles in cross-section showing vertical plication of atrialized right ventricle $(R V)$. In Carpentier method or its modification, plication procedure is not simple folding of right ventricular free wall (left). Instead, right ventricular free wall is folded against septum (right). When there is rightward deviation of posterior descending branch, branch compromise would be more likely in adjacent than in free wall plication. $L V$, Left ventricle.

the fact that the atrialized chamber consists of two major components: the interventricular septum and the inferior wall of the right ventricle. A question that came to our mind is which structure should be plicated if plication is necessary. In the discussion of the original presentation of Carpentier and associates, ${ }^{4}$ Danielson commented that it is the free wall of the right ventricle, and not the septum, that should be plicated, because the septum cannot fold well as a result of its thick struc- ture. We completely agree with his opinion. If we review the plication procedure in the Carpentier method or its modification in detail, however, we realize that the plication is not the simple folding of the right ventricular free wall; rather, the right ventricular free wall is folded against the septum. We term the latter adjacent plication (Figure 2). If the posterior descending branch runs exactly on the septum, neither fold should pose a risk of the branch injury. If the rightward deviation of the proximal portion were present, however, compromise of the branch would be more likely in adjacent plication than in a free wall procedure (Figures 2 and 3, A), especially since the rightward-deviated arteries that we saw tended to descend beside the septum. In this regard, a new method advocated by $\mathrm{Wu}$ and Huang ${ }^{13}$ and their coworkers ${ }^{14}$ is worth noting. Although it shares basic concepts with the Carpentier method, namely tricuspid valve repair with vertical plication, their method of accomplishing the plication is unique. They partially resect the inferior wall of the right ventricle from the epicardial side. This external approach would enable precise recognition of the location and course of the branch. In fact, they could preserve the rightwardly deviated posterior descending branch in some of their patients by leaving the atrialized ventricular wall containing the branch as a strip of muscle. ${ }^{13}$ Their remarkable results may be attributable to elimination of the risk of injury to the branch. In their large cohort of patients, neither death nor ventricular failure was observed, ${ }^{14}$ in stark contrast to the observation that some patients undergoing the plication with endocardial stitches have died of
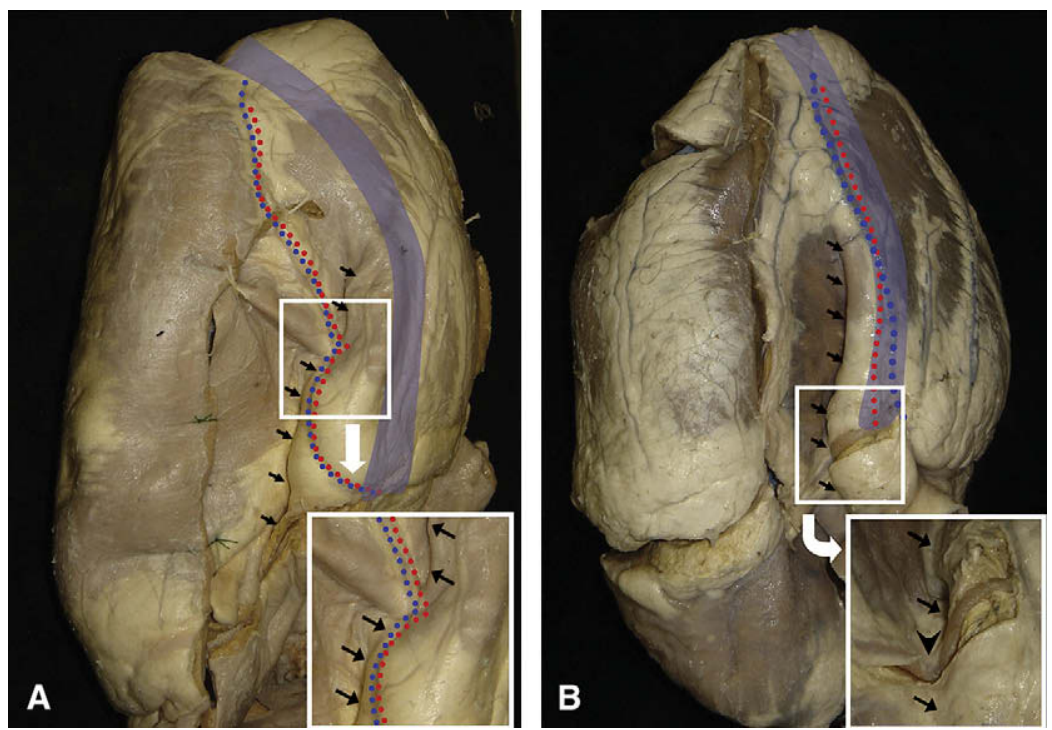

FIGURE 3. Photographs illustrating inferior wall surface of 2 hearts with Ebstein malformation displayed in same orientation as diagram in Figure 1. Longitudinal fold (between small arrows) was made in each heart to simulate surgical vertical plication of atrialized chamber. Posterior descending branch is indicated by red dotted line, and accompanying vein (middle cardiac vein) is marked by blue dotted line. A, Heart has posterior descending branch with rightward deviation. Inset in lower right corner is higher magnification of boxed area. Posterior descending branch and its venous counterpart are involved with plication procedure. B, Longitudinal suture line is extended from ventricular cavity to atrium as described in literature, ${ }^{4-6}$ so that reduction of tricuspid annulus is accomplished. In this heart, posterior descending branch runs exactly on septum and therefore is free from any compromise. This tricuspid annular reduction makes atrioventricular groove distorted, however, resulting in kinking of right coronary artery along groove (arrowhead in inset, which represents angled view of boxed area). Sutures on both heart specimens are to secure previous incisions. 
ventricular failure. ${ }^{4,5,7}$ Nevertheless, even if the branch injury is avoided, the right coronary artery itself would still be at risk of compromise, because vertical plication with concomitant reduction of the tricuspid annulus ${ }^{4-6}$ could distort the configuration of the atrioventricular groove (Figure 3,B).

Limitations of our study include the relatively small number of hearts that we examined. Another point to be raised is a possible difference in coronary distribution between an autopsy population and a clinical series, because the abnormal coronary pattern may have been related to adverse coronary events. Accordingly, it remains unclear whether these findings can reasonably be extrapolated to all hearts with Ebstein malformation. We hope that our study will stimulate future clinical investigations.

In conclusion, approximately half of the hearts with Ebstein malformation studied showed rightward deviation of the proximal portion of the posterior descending branch. This deviation allowed the branch to run on the inferior wall of the right ventricle at a proximal area from the atrioventricular junction, where stitches are placed during typical vertical plication. To avoid injury of the branch when using endocardial stitches for vertical plication of the atrialized chamber, the surgeon should inspect the course of the branch from the epicardial surface.

We express appreciation for technical advice from Mr Joseph Eliahoo at the Statistical Advisory Service, Department of Epidemiology, Public Health \& Primary Care, Faculty of Medicine, Imperial College London. We also thank Ms Manveer Sroya and Ms Carina Lim for their technical and secretarial assistances.

\section{References}

1. Becker AE, Becker MJ, Edwards JE. Pathologic spectrum of dysplasia of the tricuspid valve. Features in common with Ebstein's malformation. Arch Pathol. 1971;91:167-78.

2. Zuberbuhler JR, Allwork SP, Anderson RH. The spectrum of Ebstein's anomaly of the tricuspid valve. J Thorac Cardiovasc Surg. 1979;77:202-11.

3. Schreiber C, Cook A, Ho SY, Augustin N, Anderson RH. Morphologic spectrum of Ebstein's malformation: revisitation relative to surgical repair. J Thorac Cardiovasc Surg. 1999;117:148-55.

4. Carpentier A, Chauvaud S, Macé L, Relland J, Mihaileanu S, Marino JP, et al. A new reconstructive operation for Ebstein's anomaly of the tricuspid valve. J Thorac Cardiovasc Surg. 1988;96:92-101.

5. Chauvaud S, Berrebi A, d'Attellis N, Mousseaux E, Hernigou A, Carpentier A. Ebstein's anomaly: repair based on functional analysis. Eur $J$ Cardiothorac Surg. 2003;23:525-31.

6. Quaegebeur JM, Sreeram N, Fraser AG, Bogers AJ, Stumper OF, Hess J, et al. Surgery for Ebstein's anomaly: the clinical and echocardiographic evaluation of a new technique. J Am Coll Cardiol. 1991;17:722-8.

7. da Silva JP, Baumgratz JF, da Fonseca L, Franchi SM, Lopes LM, Tavares GM, et al. The cone reconstruction of the tricuspid valve in Ebstein's anomaly. The operation: early and midterm results. J Thorac Cardiovasc Surg. 2007;133:215-23.

8. Augustin N, Schmidt-Habelmann P, Wottke M, Meisner H, Sebening F. Results after surgical repair of Ebstein's anomaly. Ann Thorac Surg. 1997; 63:1650-6.

9. Hetzer R, Nagdyman N, Ewert P, Weng YG, Alexi-Meskhisvili V, Berger F, et al. A modified repair technique for tricuspid incompetence in Ebstein's anomaly. $J$ Thorac Cardiovasc Surg. 1998;115:857-68.

10. Ullmann MV, Born S, Sebening C, Gorenflo M, Ulmer HE, Hagl S. Ventricularization of the atrialized chamber: a concept of Ebstein's anomaly repair. Ann Thorac Surg. 2004;78:918-25.

11. Lillehei CW, Kalke BR, Carlson RG. Evolution of corrective surgery for Ebstein's anomaly. Circulation. 1967;35(4 Suppl):I111-8.

12. Angelini P. Normal and anomalous coronary arteries: definition and classification. Am Heart J. 1989;117:418-34.

13. Wu Q, Huang Z. A new procedure for Ebstein's anomaly. Ann Thorac Surg. 2004; 77:470-6.

14. Wu Q, Huang Z, Pan G, Wang L, Li L, Xue H. Early and midterm results in anatomic repair of Ebstein anomaly. J Thorac Cardiovasc Surg. 2007;134: $1438-42$. 